MATEC Web of Conferences 3, 01051 (2013)

DOI: $10.1051 /$ matecconf/20130301051

(c) Owned by the authors, published by EDP Sciences, 2013

\title{
Thermodynamic optimization of the Ho-Sn system
}

\author{
A. Iddaoudi, N. Selhaoui, S. Kardellass, M. Ait Amar, R. Karioui, K. Mahdouk, H. Najih, and L. Bouirden \\ Laboratory of Thermodynamics and Energy (L.T.E.), Faculty of science, B.P 8106, University Ibn Zohr, 80000 Agadir, \\ Morocco
}

\section{Introduction}

The alloy systems or intermetallic compounds composed of rare earth and $\mathrm{Sn}$ have attracted the attention for the magnetic materials [1]. The R-Sn binary systems generally present a high number of intermetallic compounds, often generated by peritectic reactions, and their definition has always been very complex owing to the high oxidizability of the alloys in large ranges of their composition. For this reason some of these diagrams have not been completely defined yet.

By modeling the Ho-Sn alloy, a self-consistent description of the phase relations and thermodynamic data was obtained by means of the CALPHAD technique [2] in present work.

\section{Experimental data}

The Ho-Sn binary system was investigated by Bulanova et al. [3] using thermal and microscopic analysis and reported the existence of five intermetallic compounds $\mathrm{Ho}_{5} \mathrm{Sn}_{3}, \mathrm{Ho}_{11} \mathrm{Sn}_{10}, \mathrm{HoSn}_{2}, \mathrm{Ho}_{2} \mathrm{Sn}_{5}$ and $\mathrm{HoSn}_{3}$. Later, Palenzona and Manfrinetti [4] studied the phase diagram in the Sn-rich region. For the $\mathrm{HoSn}_{2}, \mathrm{Ho}_{2} \mathrm{Sn}_{5}$ and $\mathrm{HoSn}_{3}$ compounds, a peritectic formation were reported respectively at $1403 \mathrm{~K}, 793 \mathrm{~K}$, and $693 \mathrm{~K}$.

Recently, by X-ray diffraction and microscopy technique, Bulanova et al [5] reinvestigated the system; seven intermetallic compounds were reported $\left(\mathrm{Ho}_{5} \mathrm{Sn}_{3}\right.$, $\mathrm{Ho}_{5} \mathrm{Sn}_{4}, \mathrm{Ho}_{11} \mathrm{Sn}_{10}, \mathrm{Ho}_{4} \mathrm{Sn}_{5}, \mathrm{HoSn}_{2}, \mathrm{Ho}_{2} \mathrm{Sn}_{5}$ and $\mathrm{HoSn}_{3}$ ). For the $\mathrm{Ho}_{5} \mathrm{Sn}_{3}$ compound, a congruent melting was estimated at $2188 \mathrm{~K}$, while the $\mathrm{Ho}_{5} \mathrm{Sn}_{4}, \mathrm{Ho}_{11} \mathrm{Sn}_{10}, \mathrm{Ho}_{4} \mathrm{Sn}_{5}$, $\mathrm{HoSn}_{2}, \mathrm{Ho}_{2} \mathrm{Sn}_{5}$ and $\mathrm{HoSn}_{3}$ compounds, a peritectic formation was reported, respectively, at $1993 \mathrm{~K}, 1865 \mathrm{~K}$, $1417 \mathrm{~K}, 1387 \mathrm{~K}, 782 \mathrm{~K}$ and $693 \mathrm{~K}$.

Meschel and Kleppa [6] measured the standard enthalpy of formation of $\mathrm{Ho}_{5} \mathrm{Sn}_{3}$ using the differential calorimetry method. Colinet et al. [7] and Witusiewicz et al. [8] calculated the enthalpies of formation for four intermetallic compounds: $\mathrm{Ho}_{5} \mathrm{Sn}_{3}, \mathrm{Ho}_{5} \mathrm{Sn}_{4}, \mathrm{HoSn}_{2}$ and $\mathrm{HoSn}_{3}$. The enthalpies of formation of $\mathrm{HoSn}_{2}$ and $\mathrm{HoSn}_{3}$ has been measured respectively, by Lebedev et al. [9] and Yamshchikov et al. [10] using the electromotive force measurements method. Bulanova et al [5] measured the enthalpies of dissolution of Ho in liquid Sn at $1473 \mathrm{~K}$.

\section{Results and discussions}

The optimization of the thermodynamic parameters was carried out by using the PARROT [11] module of the Thermo-Calc software [12], which is based on a least square procedure. The parameters for the liquid phase were first optimized by the experimental data of phase diagram and thermodynamics of the liquid. The congruent intermetallic compound is going to be investigated next. The other compounds were consequently optimized by using phase diagram data reported by Bulanova et al [5] and thermodynamic information of the compounds. All the parameters were evaluated and listed in Table 1.

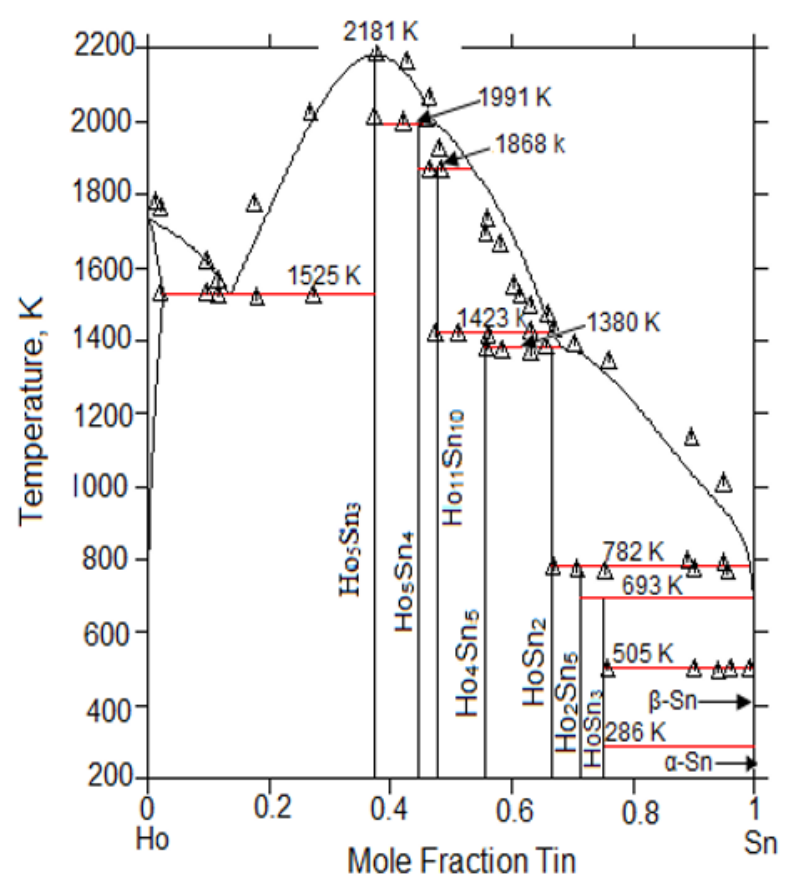

Figure 2. The calculated phase diagram of the Ho-Sn system compared with the experimental data [4].

Fig. 1 shows the calculated equilibrium phase diagram with all experimental data used in the optimization. A 
satisfactory agreement is noted in most of experimental data. The calculated invariant reactions of the Ho-Sn system are listed in table 2 and compared with the experimental results from [5]. The assessed enthalpies of formation of the intermetallic compounds compared with experimental measurements are plotted in Fig. 4 and Table 3. The calculated enthalpies agree well with the experimental data $[6,10]$.

Table 2. Invariant reactions in the Ho-Sn system.

\begin{tabular}{|c|c|c|c|c|}
\hline \multirow{2}{*}{ Reaction } & \multicolumn{2}{|c|}{$\begin{array}{l}\text { Bulanova } \\
\text { et al [4]. }\end{array}$} & \multicolumn{2}{|c|}{ This work } \\
\hline & $\mathrm{T}(\mathrm{K})$ & & $\mathrm{T}(\mathrm{K})$ & \\
\hline $\mathrm{Liq} \leftrightarrow \beta \mathrm{Sn}+\mathrm{HoSn}_{3}$ & 2 & 0.999 & 505 & 1 \\
\hline $\mathrm{Liq}+\mathrm{HoSn}_{3} \leftrightarrow \mathrm{Ho}_{2} \mathrm{Sn}_{5}$ & 693 & 995 & 693 & .998 \\
\hline $\mathrm{Liq}+\mathrm{Ho}_{2} \mathrm{Sn}_{5} \leftrightarrow \mathrm{HoSn}_{2}$ & 782 & 992 & 782 & 0.992 \\
\hline $\mathrm{Liq}+\mathrm{HoSn}_{2} \leftrightarrow \mathrm{Ho}_{4} \mathrm{Sn}_{5}$ & 1387 & 700 & 1380 & 0.683 \\
\hline $\mathrm{Liq}+\mathrm{Ho}_{4} \mathrm{Sn}_{5} \leftrightarrow \mathrm{Sn}_{10} \mathrm{Ho}_{11}$ & 1417 & 660 & 1423 & 0.666 \\
\hline $\mathrm{Liq}+\mathrm{Sn}_{10} \mathrm{Ho}_{11} \leftrightarrow \mathrm{Ho}_{5} \mathrm{Sn}_{4}$ & 1865 & 490 & 1868 & 0.535 \\
\hline $\mathrm{Liq}+\mathrm{Ho}_{5} \mathrm{Sn}_{4} \leftrightarrow \mathrm{Ho}_{5} \mathrm{Sn}_{3}$ & 1993 & 0.460 & 1991 & 0.474 \\
\hline $\mathrm{Liq} \leftrightarrow \mathrm{Ho}_{5} \mathrm{Sn}_{3}$ & 2188 & - & 2181 & - \\
\hline $\mathrm{Liq} \leftrightarrow \mathrm{Ho}+\mathrm{Ho}_{5} \mathrm{Sn}_{3}$ & 1525 & 130 & 1525 & 0.135 \\
\hline
\end{tabular}

Table 4. Calculated and measured enthalpies of formation of the intermetallic compounds.

\begin{tabular}{|l|l|l|l|}
\hline Phase & \multicolumn{1}{|c|}{$\begin{array}{c}\Delta \mathrm{H}_{\text {formation }} \\
\left(\mathrm{kJ} \mathrm{mol}^{-1} \mathrm{at}^{-1}\right)\end{array}$} & $\begin{array}{c}\text { Technique } \\
\text { used }\end{array}$ & Reference \\
\hline \multirow{4}{*}{$\mathrm{Ho}_{5} \mathrm{Sn}_{3}$} & $-73.5 \pm 2.3$ & Calorimetry & {$[6]$} \\
\cline { 2 - 4 } & -59 & Estimation & {$[7]$} \\
\cline { 2 - 4 } & $-62 \pm 5$ & Estimation & {$[8]$} \\
\cline { 2 - 4 } & -71.1 & Optimization & This work \\
\hline $\mathrm{Ho}_{5} \mathrm{Sn}_{4}$ & $-68 \pm 6$ & Estimation & {$[8]$} \\
\cline { 2 - 4 } & -66 & Estimation & {$[7]$} \\
\cline { 2 - 4 } & -74.3 & Optimization & This work \\
\hline $\mathrm{HoSn}_{2}$ & $-64.3 \pm 0.9$ & emf & {$[9]$} \\
\cline { 2 - 4 } & -55 & Estimation & {$[7]$} \\
\cline { 2 - 4 } & -65.3 & Modélisation & This work \\
\hline $\mathrm{HoSn}_{3}$ & $-48.2 \pm 0.65$ & emf & {$[10]$} \\
\cline { 2 - 4 } & -42 & Estimation & {$[7]$} \\
\cline { 2 - 4 } & $-43 \pm 6$ & Estimation & {$[8]$} \\
\cline { 2 - 4 } & -48.9 & Optimization & This work \\
\hline $\mathrm{Ho}_{2} \mathrm{Sn}_{5}$ & -56 & Optimization & This work \\
\hline $\mathrm{Ho}_{4} \mathrm{Sn}_{5}$ & -71.7 & Optimization & This work \\
\hline $\mathrm{Ho}_{11} \mathrm{Sn}_{10}$ & -75.9 & Optimization & This work \\
\hline
\end{tabular}

\section{Conclusion}

The present work reviewed critically the experimental information on phase diagram and thermodynamic properties of the Ho-Sn binary system in published literature. A set of self-consistent thermodynamic parameters formulating the Gibbs energies of various phases in the Bi-Ni binary system were obtained, which can reproduce well most of the experimental data on thermodynamic properties and phase diagram.

\section{References}

1. X.C. Zhong, M. Zou, H. Zhang, Z.W. Liu, D.C. Zeng et al, J. Appl. Phys. 109 07A917 (2011)

2. L. Kaufman and H. Bernstein, Computer Calculations of Phase Diagrams, Academic Press, New-York, NY (1970)

3. M.V. Bulanova and P.S. Martsenjuk, Poroshk. Metall. $582(1991)$

4. Palenzona, P. Manfrinetti, J. Alloys. Compd. 20143 (1993)

5. M.V. Bulanova, V.N. Eremenko, V.M. Petjukh, V.R. Sidorko, J. Phase Equilib. 19136 (1998)

6. S.V. Meschel, O.J. Kleppa, J. Alloys Compd. 238180 (1996)

7. C. Colinet, A. Pasturel, J. Less-Common Met. 102 167 (1984)

8. V.T. Witusiewicz, V.R. Sidorko, M.V. Bulanova, J. Alloys. Compd. 248233 (1997)

9. V.A. Lebedev, Y.I. Kober, L.E Yamshchikov, Thermochemistry of Alloys of Rare Earth and Actinoid Elements, Tchelyabinsk, Metallurgia 1989

10. L.F. Yamshchikov, V.A. Lebedev, S.R Raspopin, P.A. Arhipov, Izv. V.U.Z. Tsvetn. Metall. 483 (1984)

11. B. Jansson, Thesis, Royal Institute of Technology, Stockholm, 1984

12. B. Sundman, J.-O. Andersson, Calphad 9153 (1985) 